recommend urgent action to address this catastrophe in the making.

\section{P4.110 FOOD INSECURITY ASSOCIATED WITH ANTIRETROVIRAL THERAPY ADHERENCE AMONG HIV-INFECTED PATIENTS IN KINSHASA}

B Bepouka, H Situakibanza, F Kiazayawoko, M Mbula. University of Kinshasa, Kinshasa Democratic republic of Congo

\subsection{6/sextrans-2017-053264.605}

Introduction Food insecurity is increasingly reported as an important barrier of patient adherence to antiretroviral therapy(ART) in both resource-poor and rich settings. The objective of this study was to determine if food insecurity is associated with poor ART adherence among HIV-positive adults in a resource-limited setting.

Methods The study was a cross-sectional, conducted in Kinshasa, Democratic republic of Congo(DRC). We randomly selected patients and 9 support structures for PLHIV, from May 2015 to August 2015. Food insecurity was measured by the Household Food Insecurity Access Scale (HFIAS). Adherence was assessed by the pharmacy refill and case adherence index.Multivariate regression was used to assess whether food insecurity was associated with ART adherence.

Results Among 400 participants, 56\% were food insecure, $30 \%$ were mildly or moderately food insecure and $70 \%$ were severely food insecure. Side effects (OR 2.230, 1.327 to $3.747, \mathrm{p}=0.002$ ), and payment of consultation (OR 1.703, 1.020 to $2.843, \mathrm{p}=0,042$ ) were also associated with poor adherence.

Conclusion household food insecurity is present in more than half of the HIV-positive adults attending ART clinics in Kinshasa, and is associated with poor ART adherence.

\section{P4.111 AN APPRAISAL OF COMPREHENSIVE KNOWLEDGE OF HIVIAIDS AMONG INDIAN WOMEN: EVIDENCE FROM NATIONAL FAMILY HEALTH SURVEY FOURTH ROUND}

Deepanjali Vishwakarma. International Institute For Population Sciences, Mumbai, India

10.1136/sextrans-2017-053264.606

In order to design the suitable HIV prevention programs that help to reduce in HIV infections especially among Indian women's, it is essential to inspect the comprehensive knowledge of HIV/AIDS and prevention methods in terms of knowledge of consistence condom use among Women's. This paper explores comprehensive knowledge of HIV/AIDS among women's across the different states of India. Data were drawn from the National Family Health Survey 2015-16 (NFHS-4). The study included data of women aged 15-49 years. Results clearly reveal that Comprehensive knowledge of HIV/AIDS was significantly decline in many states like Bihar, Karnataka, Madhya Pradesh and Manipur. Compared to men, women had less comprehensive knowledge of HIV/AIDS across the states of India. There is no relation built between women education and knowledge about HIV/AIDS, results portrays that despite of having 10 or more years of schooling women's are not aware about HIV/ AIDS. Even gap between knowledge about HIV/AIDS and consistent condom use among women is significantly high varies from 23 to 49 percent across different states of India.
Interventions are needed to build knowledge of HIV/AIDS transmission and prevention methods through mass media campaigns, and information, education and communication programs so that women can get proper knowledge.

\section{P4.112 ASSOCIATIONS OF HIV TESTING WITH ANXIETY AND STRESS: IMPLICATIONS FOR FAITH BASED HIV TESTING AND TREATMENT}

Jennifer Stewart. Johns Hopkins University School of Nursing, Department of Community Public Health, Baltimore, USA

\subsection{6/sextrans-2017-053264.607}

Introduction The African American church has recently embraced a non-traditional venues perspective by incorporating HIV testing into the formal support services provided to the community. Mental health related indicators such as anxiety and stress are often associated with a lack of HIV testing. Social support from individuals and institutions within the African American community may have an important role in reducing stress and anxiety associated with HIV testing.

Methods In this cross-sectional survey based study, we surveyed and compared the responses of the congregants from two churches which offered testing and two which did not $(n=177)$. Data were analysed with descriptive statistics, Chisquare test and multivariate logistic regression

Results We found that in churches without HIV testing anxiety was significantly higher $(\mathrm{OR}=4.60, \mathrm{p}<0.001 ; 95 \% \mathrm{CI}: 2.03$, $10.41)$ as was levels of stress $(\mathrm{OR}=6.87, \mathrm{p}<0.001 ; 95 \% \mathrm{CI}$ : $2.69,17.56)$ after controlling for gender and employment status.

Conclusion These results have implications for the important role that African American churches could have in not only offering HIV testing but in reducing associated levels of stress and anxiety. They also suggest that churches willing to incorporate HIV risk reduction programs and interventions may have more profound impacts on the mental health of at risk populations.

\section{P4.113 REACH AND ACCEPTABILITY OF AN ONLINE HIV/STI TESTING SERVICE (GETCHECKEDONLINE) AMONG GAY, BISEXUAL, AND OTHER MEN WHO HAVE SEX WITH MEN LIVING IN BRITISH COLUMBIA, CANADA}

${ }^{1}$ Joshun Dulai, ${ }^{2}$ Travis Salway, ${ }^{2}$ Kimberly Thomson, ${ }^{2}$ Devon Haag, ${ }^{3}$ Nathan Lachowsky, ${ }^{4}$ Daniel Grace, ${ }^{5}$ Joshua Edward, ${ }^{2}$ Troy Grennan, ${ }^{6}$ Terry Trussler, ${ }^{2}$ Mark Gilbert. ${ }^{1}$ Columbia University, New York, USA; ${ }^{2}$ British Columbia Centre for Disease Control, Vancouver, Canada; ${ }^{3}$ University of Victoria, Victoria, Canada; ${ }^{4}$ University of Toronto, Toronto, Canada; ${ }^{5}$ Health Initiative for Men, Vancouver, Canada; ${ }^{6}$ Community-Based Research Centre for Gay Men's Health, Vancouver, Canada

\subsection{6/sextrans-2017-053264.608}

Introduction Gay, bisexual, and other men who have sex with men (MSM) in British Columbia (BC) have a high incidence of HIV/STI, with many reporting barriers to accessing testing. An online HIV/STI testing service, Get Checked Online (GCO), was launched in 2014 to reduce these barriers. In this study we examined reach and acceptability of GCO within the MSM community.

Methods We surveyed MSM living in BC over 6 months in 2016. Participants were recruited at local pride events, bars, on the street, in sexual health clinics, through social media, 